\title{
Comparison of Tissue Stiffness Using Shear Wave Elastography in Men with Normal Testicular Tissue, Testicular Microlithiasis and Testicular Cancer
}

\section{(ㅇ) $(\Theta \Theta$}

\author{
Authors \\ Malene Roland Pedersen 1, 2,3, Henrik Møller4, 5, Palle Jørn Sloth Osther2,3, Peter Vedsted5, 6, René Holst ${ }^{3,7}$, \\ Søren Rafael Rafaelsen ${ }^{1,3}$
}

\section{Affiliations}

1 Department of Radiology, Clinical Cancer Centre, Vejle Hospital, Part of Lillebaelt Hospital, Denmark

2 Urological Research Centre, Vejle Hospital, Part of Lillebaelt Hospital, Denmark

3 Institute of Regional Health Research, University of Southern Denmark, Odense, Denmark

4 Cancer Epidemiology and Population Health, King's College London, United Kingdom

5 Research Unit for General Practice, Department of Public Health, Aarhus University, Aarhus, Denmark

6 Department of Clinical Medicine, Aarhus University, Denmark

7 Oslo Centre for Biostatistics and Epidemiology, Department of Biostatistics, University of Oslo

Key words

elastography, ultrasonography, testicular microlithiasis, scrotum, testis cancer

received 15.01 .2017

revised 10.05 .2017

accepted 22.06.2017

Bibliography

DOI https://doi.org/10.1055/s-0043-116660

Ultrasound Int Open 2017; 3: E150-E155

(c) Georg Thieme Verlag KG Stuttgart . New York

ISSN 2199-7152
Correspondence

Mrs. Malene Roland Pedersen, phd student

Vejle hospital - Part of Hospital Lillebaelt,

Department of Radiology, Beriderbakken 4,

7100 Vejle

Denmark

malene.roland.vils.pedersen@rsyd.dk

\section{ABSTRACT}

Objectives To compare elastography measurements in men with normal testicular tissue, testicular microlithiasis and testicular cancer.

Methods A total of 248 consecutive patients were included. All men provided written informed consent. Testicular stiffness was assessed using shear wave elastography (SWE). Three SWE velocity measurements were assessed in each testicle. The patients were divided into three groups; men with normal testicular tissue $(n=130)$, men with testicular microlithiasis $(n=99)$ and men with testicular cancer $(n=19)$.

Results We found a higher mean velocity in the group of patients with testicular cancer $(1.92 \mathrm{~m} / \mathrm{s}(95 \% \mathrm{Cl} 1.82-2.03))$ compared to both the group with normal tissue $(0.76 \mathrm{~m} / \mathrm{s}(95 \%$ $\mathrm{Cl}: 0.75-0.78))(\mathrm{p}<0.001)$ and the group with testicular microlithiasis $0.79 \mathrm{~m} / \mathrm{s}(95 \% \mathrm{Cl}: 0.77-0.81)(\mathrm{p}<0.001)$.

Conclusion The presence of testicular microlithiasis increased stiffness slightly, but within the range of variation in normal testicles. Increased stiffness may indicate testicular malignancy in testicular lesions. Ultrasound elastography could be a very useful tool when investigating scrotum.

\section{Introduction}

Ultrasonography (US) is the preferred and widely accepted first choice imaging modality for the evaluation of testicular abnormalities [1]. B-mode US has a very high sensitivity when investigating the scrotum. Furthermore, new additions to B-mode US such as color Doppler, contrast-enhanced ultrasound, and recently elastography have been developed over time [2]. Elastography is a noninvasive method to evaluate tissue stiffness [3], which can be

assessed by either strain or shear wave. Strain elastography uses external transducer compression and continuously compresses the tissue of interest [4], whereas shear wave is a quantitative method [5-7]. Since lesions in testicles are superficial, both elastography methods could be used. However, elastography should be recommended as part of a multiparametric ultrasound examination approach, also suggested by Sidhu [8]. 
- Table 1 Estimated shear wave elastography stiffness in testicles with normal tissue, testicular microlithiasis, and cancer.

\begin{tabular}{|c|c|c|c|c|}
\hline $\begin{array}{l}\text { Estimated } \\
\text { values * }\end{array}$ & $\begin{array}{l}\text { Mean } \\
(\mathrm{m} / \mathrm{s})\end{array}$ & S.E. & $95 \% \mathrm{Cl}$ & P-value \\
\hline $\begin{array}{l}\text { Normal } \\
\text { testicular } \\
\text { tissue } \\
(n=130)\end{array}$ & 0.76 & 0.006 & $0.75-0.78$ & 0.027 \\
\hline $\begin{array}{l}\text { Testicular } \\
\text { microlithiasis } \\
(\mathrm{n}=99)\end{array}$ & 0.79 & 0.008 & $0.77-0.81$ & 0.02 \\
\hline $\begin{array}{l}\text { Testicular } \\
\text { cancer } \\
(n=19)\end{array}$ & 1.92 & 0.059 & $1.80-2.03$ & $<0.001$ \\
\hline
\end{tabular}

Abbreviation: $\mathrm{m} / \mathrm{s}=$ meters per second; S.E. = standard error; $\mathrm{Cl}=$ confidence interval; $\mathrm{TML}=$ testicular microlithiasis; ${ }^{*}$ The mean testicular stiffness values predicted by the random effects models when adjusted for random effects among patients, between testicles, and measurement errors

- Table 2 Random variations between the patients and the testicles from the empirical elastography measurements.

\begin{tabular}{|l|c|c|}
\hline Source of random variation & Variance & $\begin{array}{c}\text { Proportion } \\
\text { variance } \\
\text { (\%) }\end{array}$ \\
\hline Between patients & 0.0026242 & 2.6 \\
\hline Between testicles & 0.0129973 & 62.1 \\
\hline Residual/measurement error & 0.0098929 & 35.3 \\
\hline Total & 0.0255144 & 100 \\
\hline
\end{tabular}

Elastography is used in various organs $[7,9-11]$ and also in the testicles for investigating testicular torsion $[12,13]$, testicular cancer $[14,15]$ infarction $[16,17]$, epidermoid cysts [18], undescended testes [19], infertile men [20], hemodialysis patients [21], testicular microlithiasis, and other lesions [22-24]. It can be challenging to distinguish hard tumors in soft tissue using only B-mode ultrasound. Therefore, elastography is instrumental in differentiating normal from pathological tissue [5]. In an elasticity phantom comparing strain and shear wave elastography, Carlsen et al. [25] showed that the two methods were equally applicable in intermediate levels of elasticity, but strain was better in hard and soft targets.

The aim of this study was to compare shear wave elastography (SWE) in patients with normal testicular tissue, TML, and testicular cancer.

\section{Materials and Methods Study population}

A total of 248 consecutive patients from the Department of Radiology were included during the period between September 2013 and March 2016. All included patients were outpatients referred by their general practitioner for a clinical US scrotal examination due to symptoms such as pain, discomfort, lump or testicular mass. The exclusion criteria were torsion, inflammation, previously diagnosed testicular cancer, an age of less than 18 years or any linguistic difficulties regarding understanding of the informed consent. The patients were divided into three groups: normal testicular tissue, TML, and testicular cancer.

\section{Elastography image technique}

All patients underwent B-mode US investigation followed by SWE. In order to avoid signal artifacts, care was taken not to compress the testicle during the elastography investigation. SRR, MRP, or one of four certified radiologists (all had more than five years of ultrasound experience and between six months to 5 years of elastography experience) performed the SWE measurements. First a B-mode investigation was performed followed by SWE. All examinations were performed separately for the right and left testicle and on the same ultrasound machine. The three SWE measurements were performed in the center, upper and lower pole. In patients with testicular cancer, the three SWE measurements were performed in the center, upper and lower pole of the lesion. If an elastography measurement error occurred, a new measurement was performed within seconds. We used a $9 \mathrm{MHz}$ linear $9 \mathrm{~L} 4$ probe for all examinations (Siemens S3000 ultrasound machine (Acuson Corporation, Siemens, Mountain View, CA, USA) with Virtual Touch ${ }^{\text {TM }}$ Tissue Quantification software). The frame rate per second (frs) was 14; the thermal index for soft tissue (TIS) was 0.8 ; the thermal index for bone (TIB) was 1.2; and the mechanical index was 1.6. A detection pulse measured the speed of the shear waves, and the shear wave velocity was quantified in meters per second from the region of interest (ROI). A B-mode image was used to place the ROI in order to perform elastography. The ROI size was a $10 \times 10 \mathrm{~mm}$ box, which could not be altered. Three shear wave velocity measurements were performed in each testicle with the patient in the supine position. The SWE results are presented in meters per second $(\mathrm{m} / \mathrm{s})$. All images and data were recorded in the Picture Archive Communication System (PACS, Easyviz Impax Workstation, Medical Insight, Valby, Denmark). Elastography is easily performed without discomfort or pain to the patient.

\section{Statistical analysis}

We estimated the mean testicular tissue stiffness in the three groups of men using a linear mixed effects model to account for the cluster structure and estimated random variation. Data constituted a hierarchy of clusters of correlated observations: multiple measurements performed on the same testicle have a higher similarity than in comparison with those performed on the contralateral testicles. Likewise, the measurements in the same man are expected to be more similar than if compared with those performed in other men. Using the linear mixed effects model, it is possible to take random variation into account that can be attributed to heterogeneity between men, and also between testicles in the estimated elastography values.

Age and TML were adjusted for in the analysis, but neither was significant in the linear mixed effects model and hence were removed from the model. The linear mixed effects model was tested for normality by qnorm-plots of the residuals, and showed no cause 

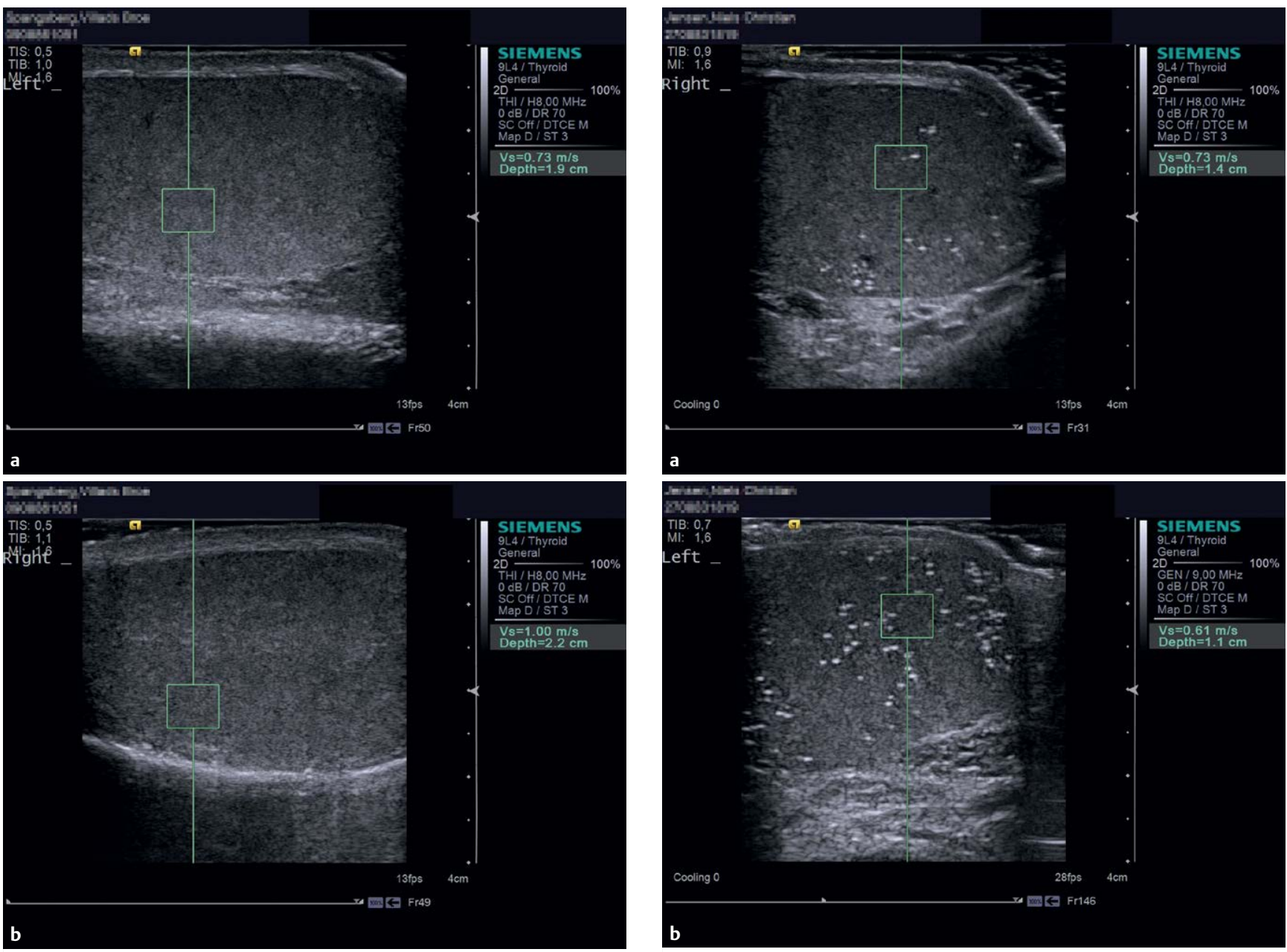

- Fig. 1 a, b Shear wave elastography of the left and right testicle of a 27-year-old man with no TML referred to an ultrasound of the scrotum due to pain.

for concern. The proportions of random variation attributed to inhomogeneity between men and between testicles (within each man), and measurement error stemming from triple measurements on each testicle was estimated.

A p-value $\leq 0.05$ was considered statistically significant. STATA statistical software (version 14.1, STATA Corporation, College Station, TX, USA) was used for the analysis.

\section{Ethics and approvals}

The Danish Data Protection Agency and The Regional Scientific Ethical Committees for Southern Denmark (ID: S-20120144) approved the study. All patients signed an informed consent after receiving both oral and written information.

\section{Results}

We included 248 consecutive patients with a total of 492 testicles (246 right testicles (146 (59.3\%) normal tissue, 90 (36.6\%) TML, 10 (4.1\%) cancers) and 246 left testicles (159 (64.6\%) normal tissue, $78(31.7 \%)$ TML, 9 (3.7\%) cancers). One of the 19 patients with testicular cancer had bilateral cancer. 

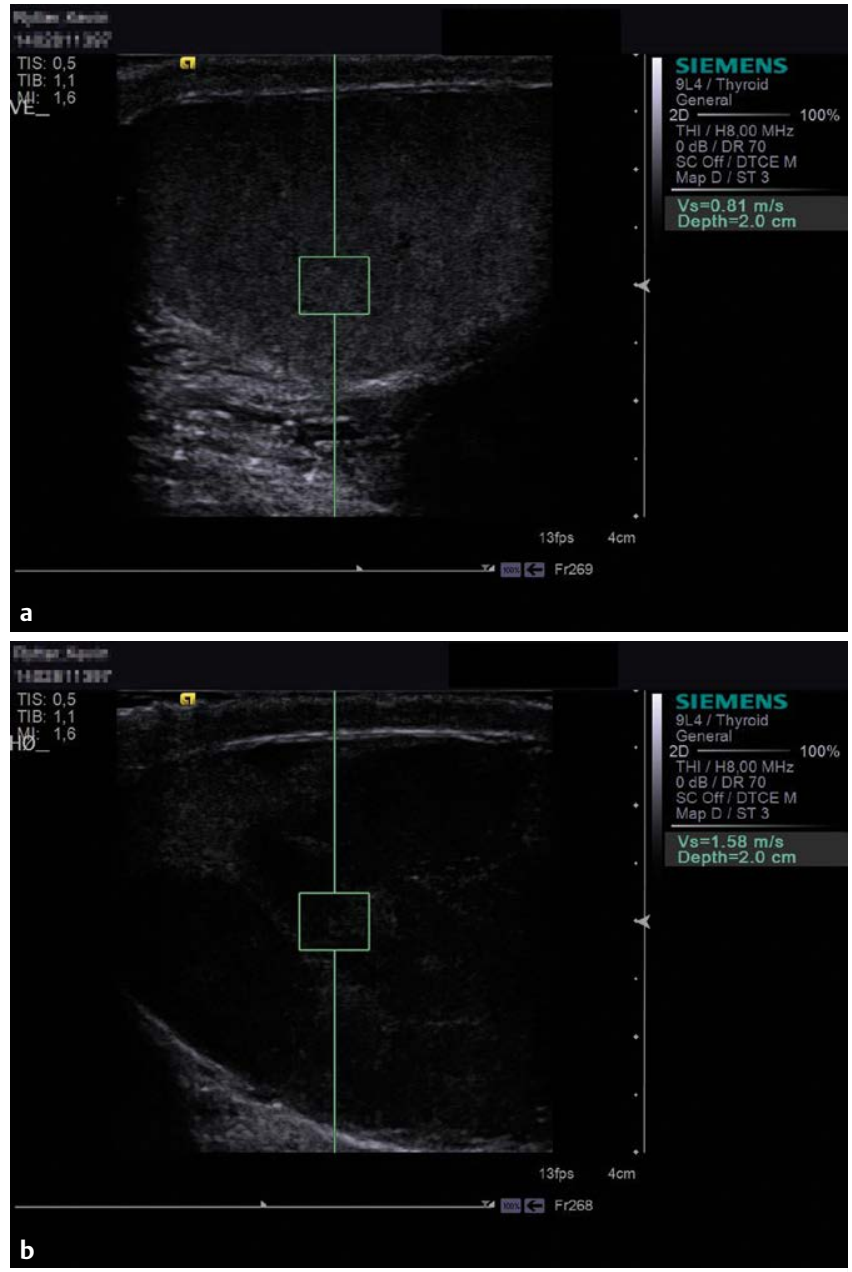

- Fig. 3 a, b Shear wave elastography of both testicles in a 31-yearold man with a tumour in the right testicle. The tumour was a seminoma with no TML. The patient was referred due to tumour suspicion.

\section{Discussion}

\section{Main findings}

We found a higher estimated statistically significant stiffness in patients with testicular cancer compared to men with normal tissue. Additionally, the stiffness in men with TML was higher than in men with normal tissue. This difference, however, is considered too small to have any clinical relevance.

\section{Comparison with other studies}

A study of thyroid nodules showed that the presence of calcifications significantly increased the stiffness [26]. We also found men with TML to have increased stiffness compared to men with normal tissue $(p=0.027)$. In our study heterogeneity between testicles belonging to the same man was responsible for nearly two-thirds of random variation (62\%), but measurement error ( $35 \%$ ) and heterogeneity between testicles (3\%) also mattered. Although the difference in stiffness between testicles with normal tissue and TML was statistically significant, it was very modest and unlikely to be of clinical importance. An explanation may be the deposition of microcalcifications throughout the testicle, as also in the thyroid gland
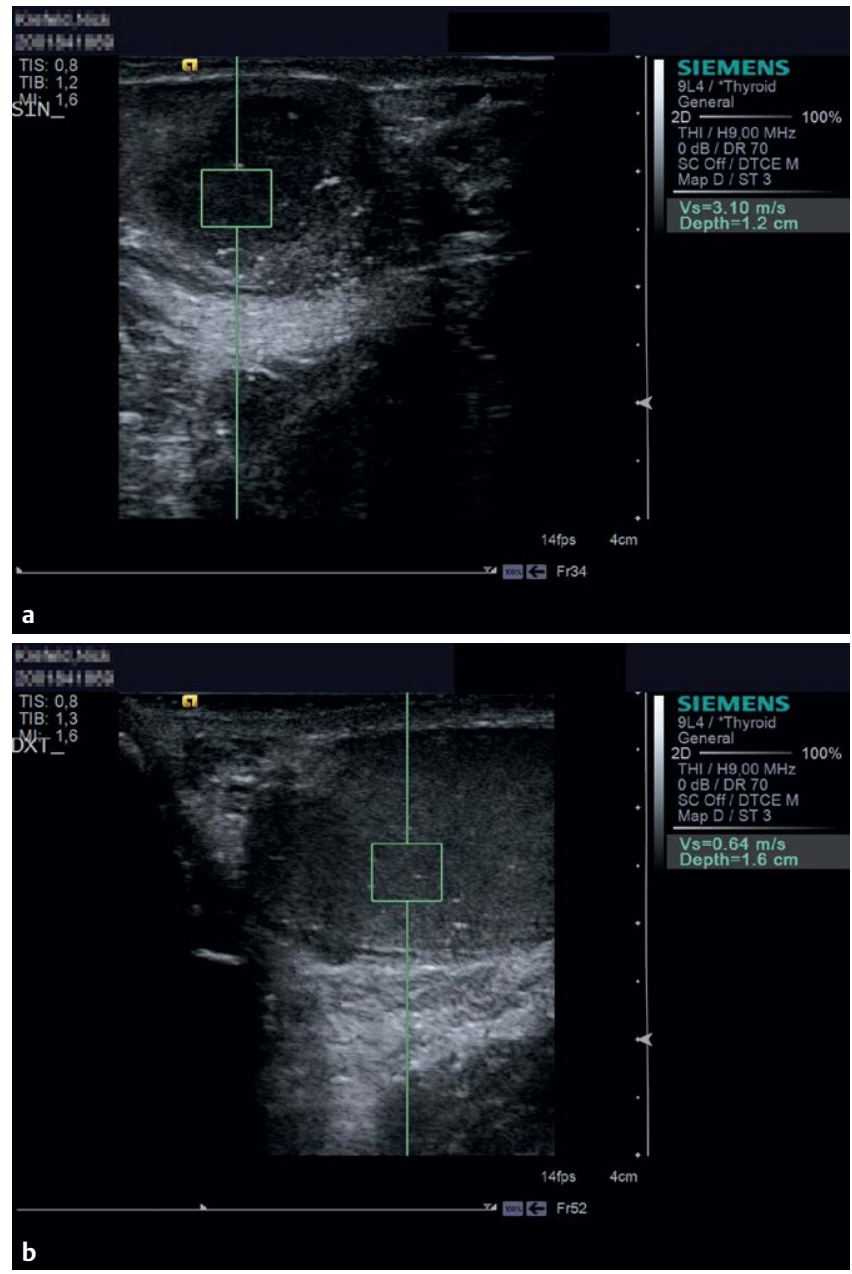

- Fig. 4 a, b Shear wave elastography of both testicles in a 29-yearold man with bilateral TML and a tumour in the left testicle. Referred to the Department of Radiology due to a lump in the left testicle.

The tumour was a seminoma.

[26]. This consideration is also shared in the recently published guidelines on TML management, recommending that a limited group of men with risk factors be offered US follow-up, since epidemiological studies and recent reports do not consider TML to be premalignant [27].

Overall, the observed mean velocity in men with testicular cancer was $2.10 \mathrm{~m} / \mathrm{s}$, but we found a calculated predicted mean of $1.92 \mathrm{~m} / \mathrm{s}$. Trottmann et al. investigated seven patients with germ cell tumors and five with seminoma using virtual touch imaging quantification (VTIQ), and the results were a mean shear wave velocity of $1.94 \mathrm{~m} / \mathrm{s}$ in germ cell tumors and $2.42 \mathrm{~m} / \mathrm{s}$ in seminoma [22]. Macron et al. investigated the testes of 20 healthy patients using SWE and found a mean SWE of $0.81 \mathrm{~m} / \mathrm{s}$ and a mean VTIQ of $1.07 \mathrm{~m} / \mathrm{s}$ [28]. VTIQ seems to measure the stiffness higher than SWE, which could be caused by the very small ROI of the VTIQ. Both studies had small sample sizes and did not take random effects into account. Variation could also be related to the ultrasound machine, transducer, and software being used. Trottman et al. also showed a statistically significant difference between mean shear wave velocity in normal testicular tissue $(1.17 \mathrm{~m} / \mathrm{s})$, seminomas $(2.42 \mathrm{~m} / \mathrm{s})$ 
and germ cell tumors $(1.94 \mathrm{~m} / \mathrm{s})(\mathrm{p}=0.002)$ [22]. An explanation for the observed velocity of $1.17 \mathrm{~m} / \mathrm{s}$ in normal testicular tissue compared to our estimated mean of $0.76 \mathrm{~m} / \mathrm{s}$ could be different elastography ultrasound machines. Another study [29] investigated 60 healthy males and found velocities at the center of the testicle to be significantly lower $(0.90 \mathrm{~m} / \mathrm{s})$ than the mean velocities of $1.15 \mathrm{~m} / \mathrm{s}$ in the inferior and superior parts of the testicles, respectively $(p<0.001)$. Whether this applies to testicular tumor tissue remains unknown.

Shin et al. compared shear wave velocities between different ultrasound machines and transducers in a phantom and found the difference in mean shear wave velocities between three machines to be statistically significant ( $p \leq 0.002$ ) [30]. This implies that caution is needed when using absolute cut-off values in the comparison of measurements from different ultrasound machines or transducers.

The main strengths of this study are the large number of patients and the inclusion of random variation in the data analysis. However, using random variation requires caution in the comparison of estimated results with observed results. We consider the use of SWE to be an asset, since it does not use manual transducer compression and therefore the testicular tissue is not displaced during measurement. Hence, SWE is operator-independent. The main limitation of this single center study is that it was only possible to obtain three velocity measurements in each testicle due to the daily workflow in our radiology department. More measurements would have yielded more precise estimates. This was also confirmed by our linear mixed effects model, which showed that increasing the number of measurements rather than the number of patients would increase the precision of the mean velocity from the three groups. Another limitation may be the relatively small number of patients with testicular malignancy $(n=19)$ included in the study. However, the mean diameter of the tumors was large in our study population, and the ROI could easily fit most lesions. Further studies including a higher number of patients with testicular lesions are warranted.

In conclusion, our study shows that the presence of TML increases stiffness slightly, but the range is still within that of normal testicles. Increased velocity may indicate testicular malignancy in testicular lesions, and the use of elastography seems a promising method for the evaluation of testicular lesions.

\section{Acknowledgements}

We would like to thank nurse Hanne Watts for efficiently enrolling patients in the study, and the radiologist colleges who performed the elastography measurements. Thanks to Karin Larsen from Department of Oncology for professional linguistic assistance. The region of Southern Denmark and the Danish Council of Radiographers supported this study.

\section{Conflicts of Interest}

The authors declare that they have no conflict of interest.
References

[1] Mihmanli I, Kantarci F. Sonography of scrotal abnormalities in adults: An update. Diagnostic and Interventional radiology 2009; 15: 64-73

[2] Rocher L, Ramchandani P, Belfield J, Bertolotto M, Derchi LE, Correas $\mathrm{JM}$ et al. Incidentially detected non-palpable testicular tumours in adults at scrotal ultrasound: Impact of radiological findings on management Radiologic review and recommendations of the ESUR scrotal imaging subcommittee. European radiology 2016; 26 : 2268-2278

[3] Bamber J, Cosgrove D, Dietrich CF, Fromageau J, Bonjunga J, Calliada F et al. EFSUMB guidelines and recommendations on the clinical use of ultrasound elastography. Part 1: Basic principles and technology. Ultraschall Med 2013; 34: 169-184

[4] Ophir ], Céspedes I, Ponnekanti H, Yazdi Y, Li X. Elastography: A quantitative method for imaging the elasticity of biological tissues. Ultrasonic imaging 1991; 13: 111-134

[5] Palmeri ML, Nightingale KR. Acoustic radiation force-based elasticity imaging methods. Interface focus 2011; 1: 553-564

[6] Nightingale K, Soo MS, Nightingale R, Trahey G. Acoustic radiation force impulse imaging: in vivi demonstration of clinical feasibility. Ultrasound Med Biol 2002; 28: 227-235

[7] Correas JM, Drakonakis E, Isidori AM, Hélénon O, Pozza C, Cantisani V et al. Update on ultrasound elastography: Miscellanea. Prostate, testicle, musculo-skeletal. European journal of radiology 2013; 82: 1904-1923

[8] Sidhu PS. Multiparametric ultrasound (MPUS) imaging: Terminology describing the many aspects of ultrasonography. Ultraschall Med 2015; 36: 315-317

[9] Yusuf G, Konstantatou E, Sellars ME, Huang DY, Sidhu PS. Multiparametric sonography of testicular hematomas: Features on grayscale, color doppler, and contrast-enhanced sonography and strain elastography. J Ultrasound Med 2015; 34: 1319-1328

[10] Rafaelsen SR, Vagn-Hansen C, Sørensen T, Lindebjerg J, Pløen J, Jakobsen A. Ultrasound elastography in patients with rectal cancer treated with chemoradiation. European journal of radiology 2013; 82: 913-917

[11] Woo H, Lee JY, Yoon JH, Kim W, Cho B, Choi BI. Comparison of the reliability of acoustic radiation force impulse imaging and supersonic shear imaging in measurement of liver stiffness. Radiology 2015; 277: 881-886

[12] Sun Z, Xie M, Xiang F, Song Y, Yu C, Zhang Y et al. Utility of real-time shear wave elastography in the assessment of testicular torsion. PloS one 2015; 10: e0138523

[13] Herek D, Herek O, Akbulut M, Ufuk F. Role of strain elastography in the evaluation of testicular torsion: An experimental study. J Ultrasound Med 2016; 35: 2149-2158

[14] Lock G, Schröder C, Schmidt C, Anheuser P, Loening T, Dieckmann KP. Contrast-enhanced ultrasound and real-time elastography for the diagnosis of benign Leydig cell tumors of the testis - a single center report on 13 cases. Ultraschall Med 2014; 35: 534-539

[15] Jedrzejewski G, Ben-Skowronek I, Wozniak MM, Brodzisz A, Budzynska E, Wieczorek AP. Testicular adrenal rest tumors in boys with congenital adrenal hyperplasia: 3D US and elastography-do we get more information for diagnosis and monitoring? Journal of pediatric urology 2013; 9 (6 Pt B): 1032-1037

[16] Kantarci F, Cebi Olgun D, Mihmanli I. Shear-wave elastography of segmental infarction of the testis. Korean journal of radiology 2012; 13: $820-822$ 
[17] Patel KV, Huang DY, Sidhu PS. Metachronous bilateral segmental testicular infarction: multi-parametric ultrasound imaging with grey-scale ultrasound, Doppler ultrasound, contrast-enhanced ultrasound (CEUS) and real-time tissue elastography (RTE). Journal of ultrasound 2014; 17: 233-238

[18] Patel K, Sellars ME, Clarke JL, Sidhu PS. Features of testicular epidermoid cysts on contrast-enhanced sonography and real-time tissue elastography. J ultrasound Med 2012; 31: 115-122

[19] Ucar AK, Alis D, Samanci C, Aslan M, Habibi HA, Dikici AS et al. A preliminary study of shear wave elastography for the evaluation of unilateral palpable undescended testes. European journal of radiology 2017; 86: 248-251

[20] Rocher L, Criton A, Gennisson JL, Izard V, Ferlicot S, Tanter M et al. Testicular shear wave elastography in normal and infertile men: A prospective study on 601 patients. Ultrasound Med Biol 2017; 43: 782-789

[21] Hekimoglu A, Tatar IG, Ergun O, Turan A, Aylı MD, Hekimoglu B Shear wave sonoelastography findings of testicles in chronic kidney disease patients who undergo hemodialysis. Eurasian J Med 2017; 49: 12-15

[22] Trottmann M, Marcon J, D'Anastasi M, Karl A, Stief CG, Reiser M et al. The role of VTIQ as a new tissue strain analytics measurement technique in testicular lesions. Clinical hemorheology and microcirculation 2014; 58: 195-209

[23] Pedersen MR, Osther PJ, Rafaelsen SR. Testicular microlithiasis and preliminary experience of acoustic radiation force impulse imaging. Acta Radiologica Open 2016; 5: 2058460116658686
[24] Rocher L, Glas L, Bellin MF, Ferlicot S, Izard V, Benoit G et al. Burnedout testis tumors in asymptomatic infertile men: Multiparametric sonography and MRI findings. J ultrasound Med 2017; 36: 821-831

[25] Carlsen JF, Pedersen MR, Ewertsen C, Saftoiu A, Lonn L, Rafaelsen SR et al. A comparative study of strain and shear-wave elastography in an elasticity phantom. AJR American journal of roentgenology 2015; 204: W236-W242

[26] Szczepanek-Parulska E, Woliński K, Stangierski A, Gurgul E, Ruchala M. Biochemical and ultrasonographic parametres influencing thyroid nodules. Endocrine 2014; 47: 519-527

[27] Richenberg J, Belfield J, Ramchandani P, Rocher L, Freeman S, Tsili AC et al. Testicular microlithiasis imaging and follow-up: guidelines of the ESUR scrotal imaging subcommittee. European radiology 2015; 25: 323-330

[28] Marcon J, Trottmann M, Rûbenthaler J, Stief CG, Reiser MF, Clevert DA. Shear wave elastography of the testes in a healthy study collective Differences in standard values between ARFI and VTIQ techniques. Clinical hemorheology and microcirculation 2016; 64: 721-728

[29] Trottmann M, Marcon J, D'Anastasi M, Bruce MF, Stief CG, Reiser MF et al. Shear-wave elastography of the testis in the healthy man -determination of standard values. Clinical hemorheology and microcirculation 2016; 62: 273-281

[30] Shin HJ, Kim MJ, Kim HY, Roh YH, Lee MJ. Comparison of shear wave velocities on ultrasound elastography between different machines, transducers, and acquisition depths: A phantom study. European radiology 2016; 26: 3361-3367 